\title{
Idiopathic Neonatal Hemorrhagic Ascites: Conservative management is an option
}

\author{
Zahraa Ezz El Din ${ }^{1}$, Amira Elrefaee ${ }^{1 *}$ \\ ${ }^{1}$ Department of Pediatrics, Faculty of Medicine, Cairo University, Egypt; zahraezzeldin@yahoo.com \\ * Correspondence: amiraelrefaee@kasralainy.edu.eg. \\ Received: 17/11/2021; Accepted: 23/12/2021; Published online: 27/12/2021.
}

\begin{abstract}
Idiopathic hemoperitoneum or hemorrhagic ascites is a very rare cause of fetal and neonatal ascites. It may be a life threatening condition which is challenging in diagnosis and treatment. We report a full term neonate who presented with cryptogenic massive hemorrhagic ascites and respiratory distress, but not anemia. All investigations failed to detect the underlying cause and attempts of therapeutic paracentesis failed due to the multilocular nature of the ascites. The ascites was self-limiting within a month. Peritoneal lavage and surgical exploration were not performed due to the regressive nature of ascites and absence of hemoglobin drop. After 18 months of follow up, the child was perfectly healthy, attained normal growth for age and did not suffer from intestinal obstruction or any other complication. Idiopathic hemorrhagic ascites can be self-limiting, conservative management and close follow up is an option.
\end{abstract}

Level of Evidence of Study: IV (1).

Keywords: Hemorrhagic ascites; anemia; surgical exploration; conservative management. Abbreviations: CT: computerized tomography; MRI: magnetic resonance imaging.

\section{Introduction}

Ascites in the newborn is rare. Accumulated ascites might be transudate, exudate, chylous, biliary, pancreatic, hemorrhagic, associated with specific infections (2) or extravasated urine (3). Ascites results from incompatibility of blood groups of mother and fetus, cardiac, hepatic, renal, pancreatic, biliary, ovarian, intestinal disease, trauma, malignancy and ruptured mesenchymal hamartoma $(2,4)$. The diagnosis is challenging and management is directed at the cause (5). Invasive procedures and surgical management is resorted in cases with ruptured viscus as urinomas,(3) etc. Hemorrhagic ascites in the newborn is rare and complicates trauma during birth, e.g. ruptured spleen or liver, ruptured omental venous malformations (6), ruptured hemangioma, or mesenchymal cyst, midgut volvulus and bleeding disorders (7). Peritoneal adhesions and frozen abdomen are serious complications of hemorrhagic ascites (8).

The aim of this work was to report a case of cryptogenic neonatal hemorrhagic ascites that underwent spontaneous resolution.

\section{Case Presentation}

A near term male newborn was delivered by cesarean section. His mother is 30 years old and had uncomplicated pregnancy, but during late antenatal ultrasound follow up, there was fetal ascites. There was no ultrasound detected fetal anemia or fluid collection in other cavities. His Apgar score was 3,5,9 at 1,5,10 minutes respectively and he was resuscitated by positive pressure ventilation and transmitted immediately to neonatal intensive care unit.

On initial examination (Figure 1), baby weight was $4100 \mathrm{gm}$ ( $90^{\text {th }}$ percentile), length was $50 \mathrm{~cm}$ (50th percentile), head circumference was $36 \mathrm{~cm}$ (50 th percentile) with striking abdominal distension (abdominal circumference was $40 \mathrm{~cm}$ 99th percentile). His heart rate was 170 beats/minute, systolic blood pressure was $76 \mathrm{mmHg}$, diastolic blood pressure was $49 \mathrm{mmHg}$ and respiratory rate was $60 /$ minute, oxygen saturation was 90 on oxygen flow $100 \%$. He was ventilated immediately due to respiratory distress and hypoxia because of severe abdominal 
distension. His initial laboratory workup showed hemoglobin $17.2 \mathrm{gm} / \mathrm{dL}$, hematocrit $53.5 \%$ and arterial blood gases showed ( $\mathrm{pH} 7.01 \mathrm{pCO}_{2} 64 \mathrm{mmHg} \mathrm{pO}_{2} 70 \mathrm{mmHg} \mathrm{HCO}_{3} 15 \mathrm{mEq} / \mathrm{L}$ ).

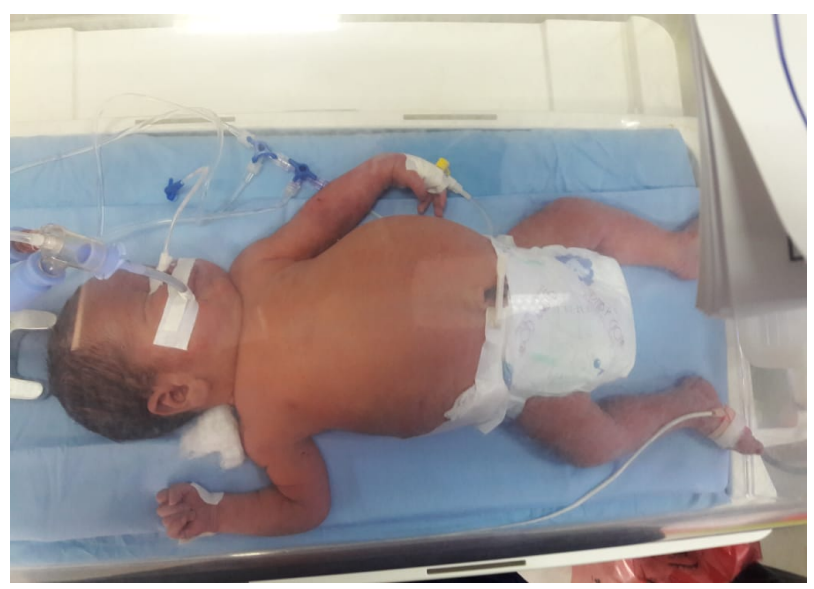

Figure 1: Affected newborn in few first hour of life on mechanical ventilation with severe abdominal distension.

Chest Xray (Figure 2) showed bilateral clear lung fields with mild obliteration of bilateral costophrenic angles and severe abdominal distension (ascites). Abdominal ultrasound showed marked peritoneal fluid collection (not encysted) with multi-septation and turbid content and bilateral hydrocele in otherwise normal structure of liver, spleen and kidneys, normal flow of mesenteric and renal blood vessels and absence of intra-abdominal masses, cysts and intestinal loop dilatation. Echocardiography showed atrio ventricular and arterio-ventricular concordance, small patent foramen oval with estimated pulmonary artery pressure $30 \mathrm{mmHg}$, no patent ductus arteriosus and no pericardial effusion.

Therapeutic ultrasound guided peritoneal tapping was done after exclusion of bleeding tendency. The fluid was non clotted dark chocolate (Figure 2; Table 1) and scanty (50 cc after two trials of paracentesis in the $1^{\text {st }}$ day of life, in $3^{\text {rd }}$ day of life). Characteristics of the peritoneal fluid is presented in table 1 .
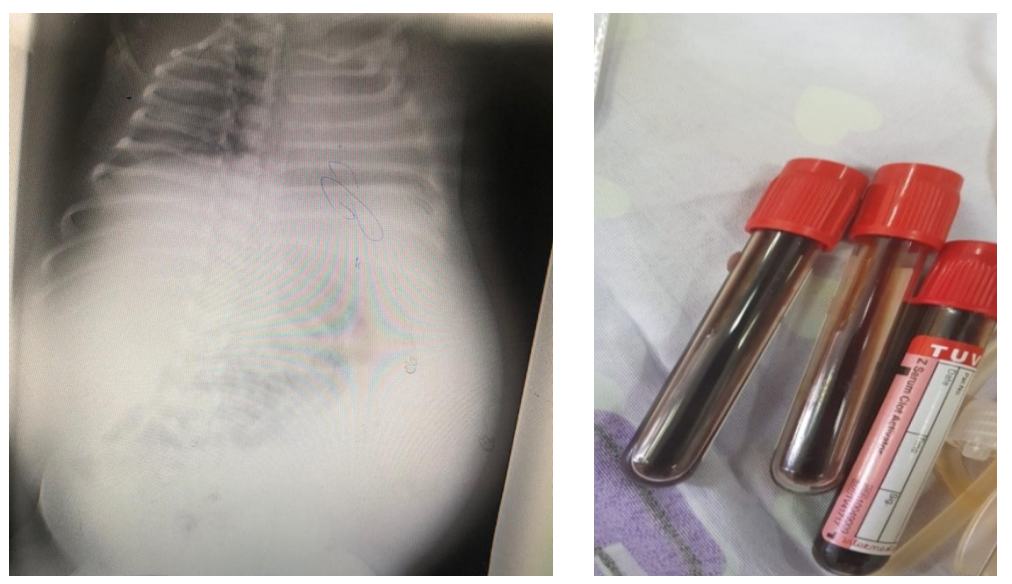

Figure 2: Initial erect chest and abdominal Xray and peritoneal fluid tapping.

Neonate was weaned from mechanical ventilator after 10 days and enteral feeding was started after stabilization and reached to full oral intake without increasing of abdominal girth or increasing in abdominal peritoneal fluid collection in follow up ultrasound. His hemoglobin level did not drop. Post contrast computerized tomography (CT) of abdomen and pelvis (Figure 3) on day 20 of life showed multiseptated fluid collection distending the abdominal and pelvic cavities and displacing both kidneys posteriorly and bowel loops anteriorly and medially with normal appearance of intra-abdominal organs and absence of intra-abdominal masses and cysts. 
MRI of the abdomen and pelvis was done at age of 25 days and showed marked pelvic abdominal ascites with high $\mathrm{T} 1$ and $\mathrm{T} 2$ signals, likely subacute hemorrhagic content or high proteinaceous content with no evidence of abdominal or pelvic soft tissue masses.

Table 1: Peritoneal fluid analysis.

\begin{tabular}{|c|c|c|c|}
\hline & Reference & Day 1 & Day 3 \\
\hline Appearance & Clear pale yellow & Chocolate red & Chocolate red \\
\hline Protein & $0.8-2.5 \mathrm{~g} / \mathrm{dL}$ & $3.3 \mathrm{~g} / \mathrm{dL}$ & $2.91 \mathrm{~g} / \mathrm{dL}$ \\
\hline Serum protein & $3.5-4 \mathrm{~g} / \mathrm{dL}$ & $3.4 \mathrm{~g} / \mathrm{dL}$ & \\
\hline Ascitic Lactate dehydrogenase & $87-244 \mathrm{U} / \mathrm{L}$ & $3937 \mathrm{U} / \mathrm{L}$ & $4700 \mathrm{U} / \mathrm{L}$ \\
\hline Serum Lactate dehydrogenase & $160-420 \mathrm{U} / \mathrm{L}$ & $1441 \mathrm{U} / \mathrm{L}$ & \\
\hline Triglyceride & $<200 \mathrm{mg} / \mathrm{dL}$ & $134 \mathrm{mg} / \mathrm{dl}$ & $156.9 \mathrm{mg} / \mathrm{dl}$ \\
\hline Serum triglyceride & $29-100 \mathrm{mg} / \mathrm{dL}$ & $75 \mathrm{mg} / \mathrm{dl}$ & \\
\hline Glucose & $\begin{array}{l}70-102 \mathrm{mg} / \mathrm{dL} \\
\text { Similar to serum }\end{array}$ & $41 \mathrm{mg} / \mathrm{dl}$ & $62 \mathrm{mg} / \mathrm{dl}$ \\
\hline Bilirubin & $0.7-0.8 \mathrm{mg} / \mathrm{dL}$ & -- & $4.78 \mathrm{mg} / \mathrm{dl}$ \\
\hline Creatinine & $<1 \mathrm{mg} / \mathrm{dL}$ & & $0.68 \mathrm{mg} / \mathrm{dl}$ \\
\hline Cells & $<5$ & RBC's 2500 & RBC's 1400 \\
\hline Culture & & \multicolumn{2}{|l|}{ No growth } \\
\hline Pathological examination & & \multicolumn{2}{|c|}{$\begin{array}{l}\text { Hemosiderin laden macrophage } \\
\text { Negative for atypical cells (Malignant } \\
\text { cells) }\end{array}$} \\
\hline Other & & \multicolumn{2}{|c|}{$\begin{array}{l}\text { No organism was seen by Gram stain } \\
\text { and Ziehl-Neelsen stain }\end{array}$} \\
\hline
\end{tabular}

The neonate was discharged after 32 days in good general condition on breast feeding with instruction about any sign of intestinal obstruction. After discharge; he followed up regularly at The Neonatology Clinic, Cairo University Children Hospital by assessment of his physical growth, abdominal circumference, hemoglobin and abdominal ultrasonography. At age of 18 months, his hemoglobin level was $9.5 \mathrm{gm} / \mathrm{dL}$, his weight and height were $13.5 \mathrm{~kg}$ and $85 \mathrm{~cm}(1.55,0.79 \mathrm{Z}$ score) respectively. (Figure 4). Abdominal ultrasound showed no fluid in the abdominal cavity and no intra-abdominal adhesions.

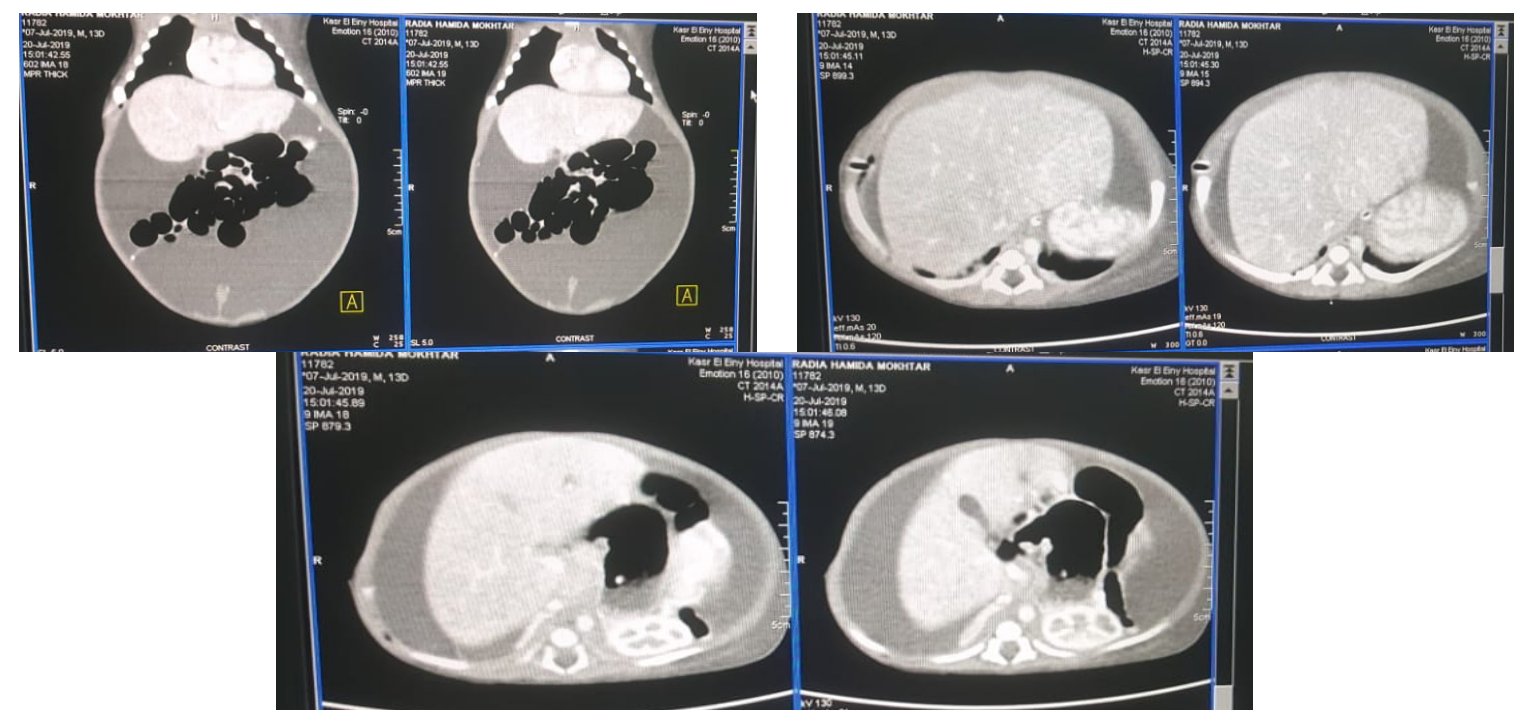

Figure 3: Post contrast CT of abdomen and pelvis.

A multiseptated fluid collection distending the abdominal and pelvic cavities and displacing both kidneys posteriorly and bowel loops anteriorly and medially with normal appearance of intraabdominal organs and ascent intra-abdominal masses and cysts. 


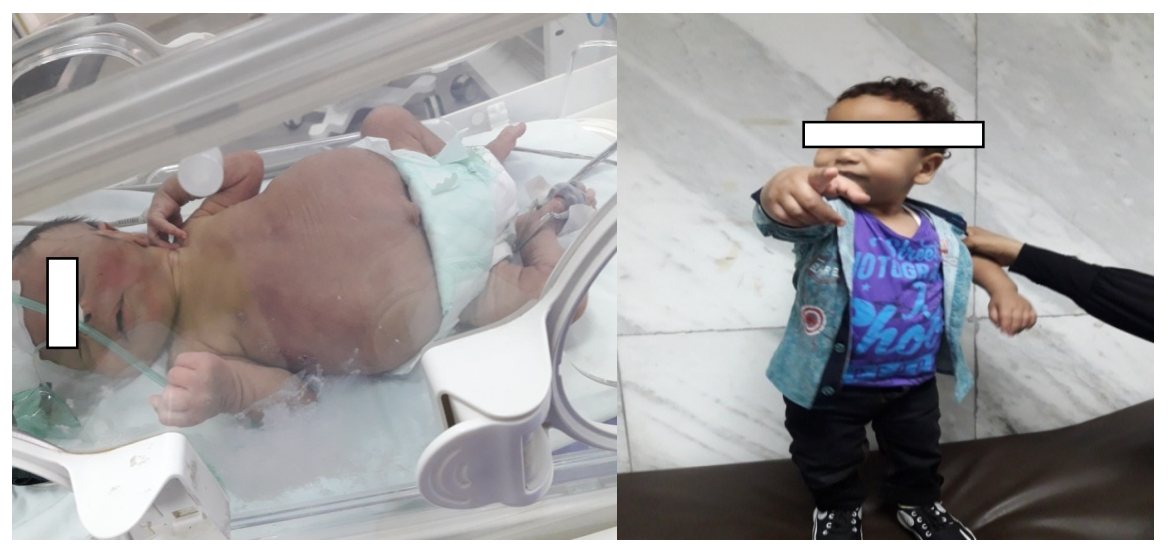

Figure 4: The neonate at 23 days of life and at 18 months.

\section{Discussion}

Clinical examination, lab investigations, imaging including ultrasound, contrast CT and MRI, diagnostic and therapeutic tapping, are the initial steps for diagnosis of the underlying cause of neonatal ascites. At times the diagnosis is straight forward as with chylous ascites, as the chylous ascites associated with congenital lymphatic malformation, ruptured thoracic duct and lymphatic obstruction has characteristic milky appearance with triglyceride level more than $200 \mathrm{mg} \%$ and protein more than $2 \mathrm{~g} \%$ (5). Our studied neonate had hemorrhagic ascites that was regressive in nature and completely resolved with conservative management. Hence, the possibility of an early intrauterine event was suspected. After exclusion of ongoing bleeding, system failures, surgical emergencies and abdominal masses with laboratory investigations and imaging, the decision of surgical exploration to detect the underlying cause was deferred. The course of the ascites lacked complications as peritoneal infections and intestinal adhesions.

All investigations done did not detect the causes of hemorrhagic ascites, e.g. large cystic mass with multiple septa of ruptured cystic mesenchymal hamartoma, or complicated necrotizing enterocolitis, iatrogenic injury during umbilical catheterization or very rarely birth trauma, although the previously mentioned causes are acquired after birth (9). Peritoneal lavage was suggested to guard against future intestinal adhesions (10) yet the neonate did not undergo peritoneal lavage as he was on mechanical ventilation initially followed by spontaneous resolution of the ascites. The non-clotting nature of the ascites was another factor that encouraged postponing the lavage, and later on abandoning it.

\section{Conclusion}

Hemorrhagic ascites in neonates is very rare, it is a life threatening condition that requires prompt management. Etiology remains obscure in some cases. Among those with suspected early intrauterine event, conservative treatment is an option if there is no anemia and no further collection of ascitic fluid. Close follow up is recommended for signs of frozen abdomen and intestinal obstruction.

Author Contributions: All authors searched medical literature, databases, conceptualized, conducted the case review and reviewed the final manuscript. All authors have read and agreed to the published version of the manuscript.

\section{FUNDING}

Authors declare there was no extramural funding provided for this study.

\section{CONFLICT OF INTEREST}

The authors declare no conflict of interest. Authors declare veracity of information.

\section{References}

1. S. Tenny, M. Varacallo, Evidence Based Medicine. (StatPearls Publishing; Treasure Island (FL), 2020; https://www.ncbi.nlm.nih.gov/books/NBK470182/). 
2. Ascitic Fluid Analysis in the Differential Diagnosis of Ascites: Focus on Cirrhotic Ascites. J. Clin. Transl. Hepatol. 2 (2014), doi:10.14218/JCTH.2013.00010.

3. A Giant Fetal Urinoma in a Neonate without Detectable Obstructive Uropathy. Eur. J. Pediatr. Surg. 13, 355-359 (2003).

4. N. H. Urrunaga, A. G. Singal, J. A. Cuthbert, D. C. Rockey, Hemorrhagic ascites. Clinical presentation and outcomes in patients with cirrhosis. J. Hepatol. 58, 1113-1118 (2013).

5. M. Kotb, D. Mosallam, H. Ragab, H. Abd El Baky, A. El Hatw, A. Hamza, H. Abd El Kader, G. El Tagy, H. Esmat, S. Shehata, N. Sabry, Management and Outcome of Chylous Ascites in Children: A CARE compliant Case Series. Pediatr. Sci. J. 1, 34-40 (2020).

6. S.-H. Nam, S. H. Koo, M. L. Chung, Y. J. Jung, H. J. Cho, J. Y. Kim, Neonatal Hemoperitoneum Secondary to Hemorrhage from Omental Venous Malformation. Pediatr. Neonatol. 56, 422-424 (2015).

7. S. A. Noreldeen, S. G. Hodgett, N. Venkat-Raman, Midgut volvulus with hemorrhagic ascites: a rare cause of fetal anemia. Ultrasound Obstet. Gynecol. 31, 352-354 (2008).

8. A. K. Bressan, A. W. Kirkpatrick, C. G. Ball, Abdominal intra-compartment syndrome - a nonhydraulic model of abdominal compartment syndrome due to post-hepatectomy hemorrhage in a man with a localized frozen abdomen due to extensive adhesions: a case report. J. Med. Case Reports. 10, 251 (2016).

9. R. M. R. Tan, J. Lee, A. Biswas, C. Amutha, Ascites, anemia and (intestinal) atresia. J. Perinatol. 34, 78-80 (2014).

10. A. Rodriguez, R. W. DuPriest, C. H. Shatney, Recognition of intra-abdominal injury in blunt trauma victims. A prospective study comparing physical examination with peritoneal lavage. Am. Surg. 48, 457-459 (1982). 